\title{
Modeling Psychrometric Data in Real-Time fruit Logistics Monitoring
}

L. Ruiz-Garcia and P. Barreiro

Laboratorio de Propiedades Físicas y

Tecnologías Avanzadas en

Agroalimentación. ETSI Agrónomos.

Universidad Politécnica de Madrid.

Madrid. Spain

J.I. Robla

Centro Nacional de Investigaciones Metalúrgicas. Consejo Superior de Investigaciones Científicas. Madrid. Spain.

Keywords: perishable products, postharvest, condensation, water lost, motes, cold chain, wireless sensor networks

\begin{abstract}
Progress in fruit logistics requires an increasing number of measurements to be performed in refrigerated chambers and during transport. Fruits and vegetables are submitted to a variety of risks during transport and storage that are responsible for material quality losses. Among them water loss and condensation are causes of deterioration that reduces the marketability of fresh fruits and vegetables. Wireless sensor networks (WSN) are a promising solution in monitoring food logistics. Instrumented with sensors, such as temperature and humidity, this technology allows on-line supply chain monitoring of perishable food products. Psychrometry studies the thermodynamic properties of moist air and the use of these properties to analyze conditions and processes involving moist air. Using the information provided by the sensors, psychrometric equations can be used for quick assessment of changes in the absolute water content of air, allowing estimation of future water loss and detection of condensation. In this paper the psychrometric data from ASABE (American Society of Agricultural and Biological Engineers) has been applied, for modeling evaporation and condensation of water related with regard to product in a refrigerated chamber. The experiments were conducted in a commercial wholesaler store in the fruit and vegetables wholesalers market of Madrid. Two different types of IEEE 802.15.4/ZigBee motes have been used.
\end{abstract}

\section{INTRODUCTION}

Effective cold-logistics monitoring is fundamental for ensuring product quality along the supply chain (Ruiz-Garcia et al., 2007). Fruits and vegetables are submitted to a variety of risks during transport and storage that are responsible for material quality losses. Among them water loss is one of the main causes of deterioration that reduces the marketability of fresh fruits and vegetables. Relative humidity (RH), the temperature (T) of the product and its surrounding atmosphere, and air velocity all affect the amount of water lost from perishable food products. Free water or condensation is also a problem as it encourages microbial infection and growth, and it can also reduce the strength of carton packing (Shamaila, 2005). 


\section{Wireless Sensor Networks}

Wireless Sensors Networks (WSN) is a very promising technology in monitoring fruit logistics. Instrumented with a variety of sensors, such as temperature, humidity and volatile compound detection, this technology allow supply chain monitoring of perishable food products to be accomplished in a distributed way. Such devices can be placed in transport vehicles in order to monitor the on-the-go environment and can be the basis for distributed systems, enabling environment sensing together with data processing (Wang et al., 2006; Ruiz-Garcia et al., 2007).

WSN can operate in a wide range of environments and provide advantages in cost, size, power, flexibility and distributed intelligence compared to wired ones. Monitoring applications have been developed in medicine, agriculture, environment, military, machine/building, toys, motion tracking and many other fields. WSN eliminates all the problems arising from wires in the system. Another advantage for wireless sensor devices is the feasibility of installation in places where cabling is impossible, such as large concrete structures or embedded within the cargo, which brings their readings closer to the true in situ properties of perishable products (Wang et al., 2006).

At the current stage there are two available standard technologies for WSN: ZigBee and Bluetooth. The ZigBee standard is built on top of the IEEE 802.15.4 standard. Both are within the Industrial Scientific and Medical (ISM) band of $2.4 \mathrm{GHz}$, which provides license-free operations, huge spectrum allocation and worldwide compatibility. ZigBee is more suitable for WSN, mainly because of its low power consumption derived from its multi-hop communication. The suitability of this standard for monitoring has been proposed by various authors (Qingshan et al, 2004; Wang et al., 2006; Ruiz-Garcia et al., 2007).

\section{Psychrometry}

The Psychrometry studies the thermodynamic properties of moist air and the use of these properties to analyze conditions and processes involving moist air. Psychrometric charts give a graphical representation of the relationship between temperature, RH and water vapor pressure in moist air (Talbot and Baird, 2002; ASABE, 2006).

The potential of these systems to evaluate water loss or condensation has not been explored. Thus, experimentation in a real environment is needed. The combination of high precision $\mathrm{T}$ and $\mathrm{RH}$ sensor with psychrometric relations allow to monitor water loss and water condensation.

The main objective of this paper is to study the performance of ZigBee motes for monitoring the refrigerated conditions in fruit chambers with low temperatures, high humidity and different cargo densities. Studying the application of psychrometric data from ASABE (American Society of Agricultural and Biological Engineers) standard in refrigerated chambers, for modeling evaporation and condensation of water related with regard to product.

\section{MATERIALS AND METHODS}

\section{Motes}

Two different types of ZigBee/IEEE 802.15.4 motes have been used: Crossbow (Xbow) and Xbee-PRO (Xbee). In both systems one sensor node (transmitter), and one 
base station (receiver), has been tested. The program installed in the motes collects data from all the sensors at a fixed sample rate (11 s for Xbow and 10 seconds for Xbee).

The Xbow motes are integrated by a microcontroller board (Micaz) together with an independent transducer board (MTS420) attached by means of a 52 pin connector (Figure 1). Power is supplied by two AA alkaline batteries. The MTS420 board hosts a variety of sensors: temperature and relative humidity (Sensirion SHT), light intensity (TAOS TSL2550D), barometric pressure (Intersema MS5534B), two-axis accelerometer (ADXL202JE) and GPS (Leadtek GPS-9546) that can be easy removed. A laptop computer is used as the receiver, and communicates with the nodes through a Micaz mounted on the MIB520 ZigBee/USB gateway board; this device also provides a USB programming interface. For this paper, only Sensirion SHT sensors were used

The XBee-PRO RF module is a ZigBee/IEEE 802.15.4 compliant solution for WSNs. Based on the Xbee-PRO development kit, we developed a prototype for monitoring. It includes an Xbee-PRO board, together with a development kit from a Sensirion SHT sensor; power for both came from a 12V 7Ah battery (Figure 2).

The SHT, the sensor that both systems have, is a single chip relative humidity and temperature multi sensor module comprising a calibrated digital output. The device includes a capacitive polymer sensing element for relative humidity and a bandgap temperature sensor. Both are seamlessly coupled to a 14bit analog to digital converter and a serial interface circuit on the same chip.

\section{Experimental work}

The experiments were conducted in a commercial wholesaler store in the fruit and vegetables wholesalers market of Madrid. This chamber has a volume of $1848 \mathrm{~m}^{3}$, provides on/off glycol cooling and is isolated with polyurethane foam, covered with corrugated plate in both sides (walls $0.16 \mathrm{~m}$ thick). The set point for this chamber was fixed to $3^{\circ} \mathrm{C}$ according to user restrictions, and in this case all the pallets has chard. Tests were also conducted to measure the effect of different cargo densities, three different conditions: free space, 13 pallets full of boxes with in between the emitter and receiver, and inside pallet number 6 .

\section{Psychrometric data}

The ASAE D271.2, defined in April 1979 and reviewed in 2005, is used for computing the psychrometric properties of air at the experiments (ASABE, 2006). Equations 1, 2, 3 and Table 1 enable the calculation of all psychrometric data of air whenever two independent psychrometric properties of an air-water vapor mixture are known in addition to the atmospheric pressure $\left(10^{5} \mathrm{~Pa}\right)$.

$$
P S=R * e^{\frac{A+B * T+C * T^{2}+D * T^{3}+E * T^{4}}{F * T-G * T^{2}}}
$$

$T=$ Temperature $\left({ }^{\circ} \mathrm{K}\right), P s=$ Saturation vapour pressure $(P a)(A S A B E, 2006)$.

$$
\begin{gathered}
P v=P s \frac{R H}{100} \\
P v=\text { Vapor pressure }(P a)(A S A B E, 2006) .
\end{gathered}
$$




$$
H=\frac{0.6219 * P v}{P a t m-P v}
$$

$H=A b s o l u t e ~ h u m i d i t y ~(g / k g$ dry air), Patm=Atmospheric pressure (Pa) (ASABE, 2006).

\section{RESULTS AND DISCUSSION}

Psychrometric charts are included in Figures 3 and 4, which illustrate the evolution of air absolute humidity $\left(\mathrm{H}, \mathrm{kg}\right.$ of water/ $\mathrm{kg}$ of dry air) related to the $\mathrm{T}\left({ }^{\circ} \mathrm{C}\right)$ for empty room, 13 pallet and emitter-inside-cargo experiments. Door opening created a great increment in $\mathrm{T}\left({ }^{\circ} \mathrm{C}\right)$ and absolute humidity, which then returns to normal again once the door is shut. During the rest of the time, it is also possible to detect the interaction between air properties and the product; with the cycles of cooling, variations in the absolute humidity can be estimated: condensation over the products (as loss of absolute humidity), or water evaporation (as an increase in absolute air humidity). The lines refer to the absolute water content for several values of RH (100\%-45\%). It can be seen in Figure 3 that temperature varies more with the empty chamber because of higher thermal inertia.

The psychrometric data for Xbow motes (Figure 3) shows a clear segregation between the three positions inside the chamber. Black dots represent air conditions with empty-chamber, blue motes refer to data from a cool loaded-room and red data represent ambient data inside the pallet. Air absolute humidity inside the pallet is always higher than air outside cargo, which indicates water loss from the product. With empty-chamber, air temperature inertia seems to be lower than for loaded-room and thus temperature variability is much higher; for this same situation, absolute humidity has lower variation.

The psychrometric chart for Xbee motes (Figure 4) shows empty-chamber data to be indistinguishable from loaded-room data. This fact may be due to the location where the sensor was situated, at the end of the cable and touching the floor of the room. As before, air absolute humidity inside the cargo is higher than for other situations, due to water loss in the product. In these types of motes - where the sensor is located far from the electronics - a clear pattern in temperature and air humidity is found which corresponds to door opening of the chamber (simultaneous increase of temperature and absolute humidity). This pattern is different for Xbow motes due to the location of the sensor (beneath the GPS device) and thus very much affected by the heat dissipating from the electronics.

\section{CONCLUSIONS}

The use of psychrometric equations has been implemented for quick assessment of changes in the absolute water content of air. A distributed system that implements this type of sensors can estimate water loss from the products using the psychrometric model, providing valuable information to improve the control algorithms of the cooling and ventilation system. Also to detect condensation on the commodities and compute the air enthalpy related with the heat transfer in the room or in a transport.

This information allows producers, packinghouse operators, and commercial cooler operators to improve postharvest cooling and storage conditions for fresh products. Featuring the possibility to correct cold chain undesirable situations, such as high temperatures and low moisture levels, reducing the spoilage and rots of their commodities.

\section{ACKNOWLEDGEMENTS}


Thanks to the SENSOFRIGO research program supported by the Ministry of Education and Science of Spain (Ref: AGL2003-06073-C02-01) and TAGRALIA project funded by the Comunidad de Madrid. The authors would like to thank also Jorge Sánchez for their help in the experiments.

\section{Literature Cited}

ASABE Standards, 2006. Psychrometric data. ASAE D271.2 APR1979, R2005. St. Joseph, MI. Available in www.asabe.org. [October 2007]

Qingshan, S., Ying, L., Gareth, D., and Brown, D., 2004. Wireless Intelligent Sensor Networks for Refrigerated Vehicle. IEEE 6th Symp. on Emerging Technologies: Mobile and Wireless Communication. Shangai, China.

Ruiz-Garcia L., Barreiro P., Rodríguez-Bermejo J., and Robla J.I., 2007. Monitoring intermodal refrigerated fruit transport using sensor networks: a review. Spanish Journal of Agricultural Research. Vol. 5, No. 2- June 2007.

Shamaila M., 2005. Produce Degradation: Pathways and Prevention. Chapter 9: Water and its relation to Fresh produce. pp. 268-287. ISBN 0849319021.

Talbot M. and Baird D., 2002. Psycrometrics and Postharvest Operations. CIR1097. Florida Cooperative Extension Service, Institute of Food and Agricultural Sciences. http://edis.ifas.ufl.edu. [January 2008]

Wang N., Zhang N., and Wang M., 2006. Wireless sensors in agriculture and food industry - Recent development and future perspective. Computer and Electronics in Agriculture, 50, 1-14.

\section{Tables}

Table 1: Coefficients used to compute the psychometric data (ASABE, 2006). According to equations 3 to 5

\begin{tabular}{cc}
\hline $\mathrm{R}=22,105,649.25$ & $\mathrm{D}=0.12558 \times 10^{-3}$ \\
$\mathrm{~A}=-27,405.526$ & $\mathrm{E}=-0.48502 \times 10^{-7}$ \\
$\mathrm{~B}=97.5413$ & $\mathrm{~F}=4.34903$ \\
$\mathrm{C}=-0.146244$ & $\mathrm{G}=0.39381 \times 10^{-2}$ \\
\hline
\end{tabular}

\section{Figures}

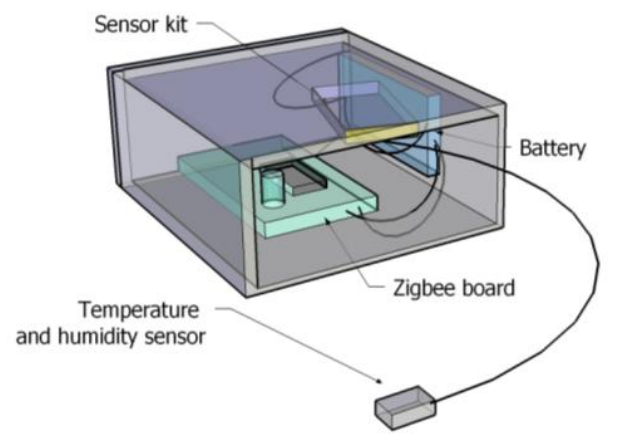




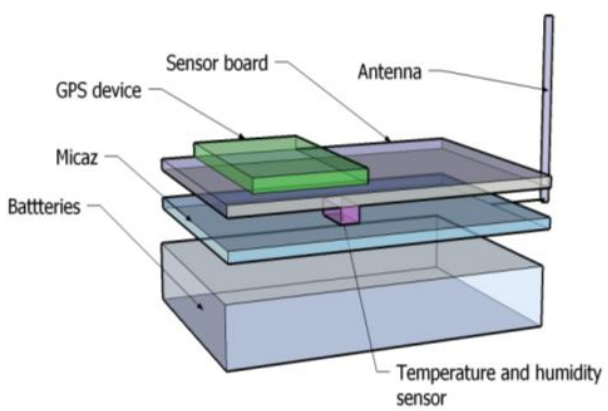

Figure 1: Xbow mote

Figure 2: Xbee based prototype

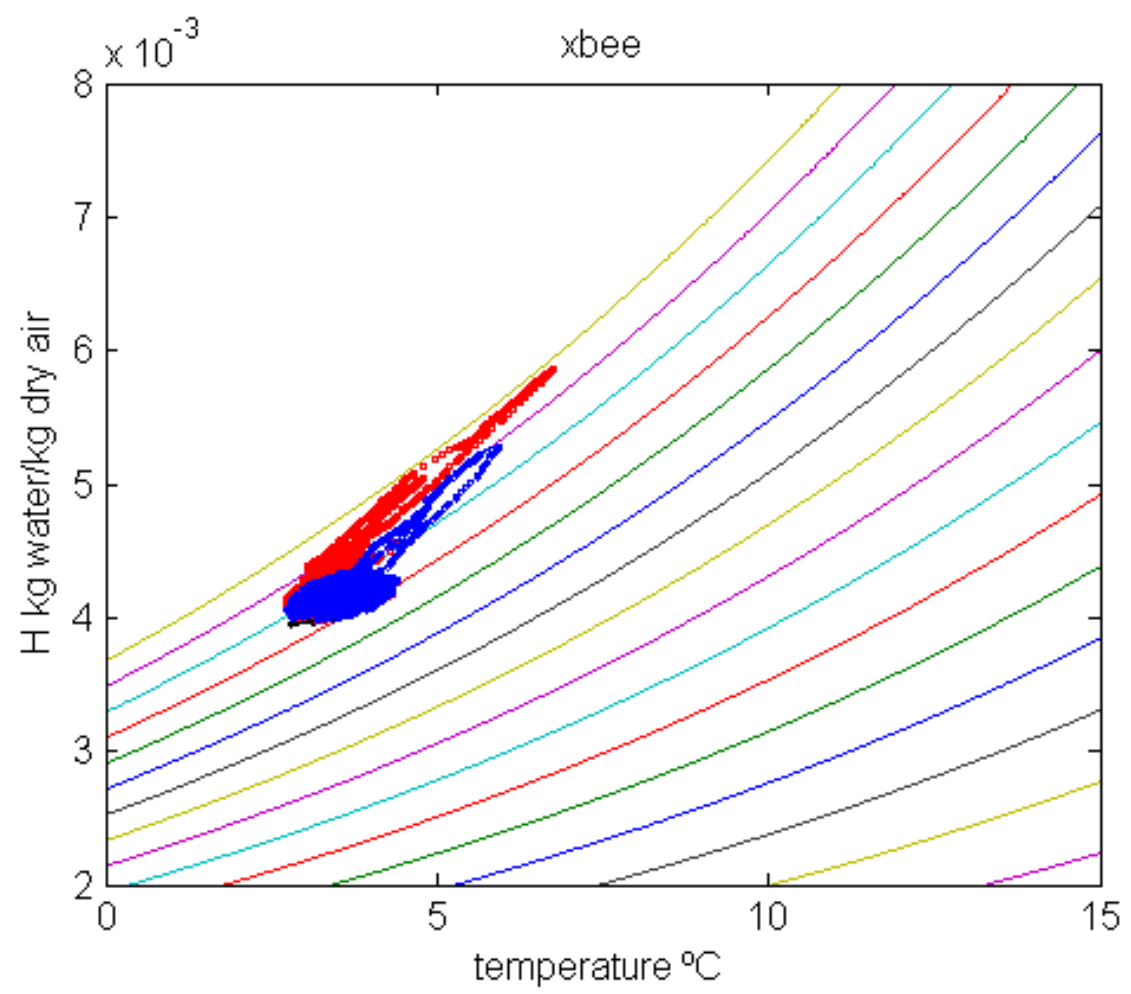

Figure 3: Psychrometric chart $\left(\mathrm{T}-{ }^{\circ} \mathrm{C}-\right.$, absolute humidity - kg/kg dry air-) for Xbee motes. Color lines indicate relative humidity between $100 \%$ and $45 \%$ 


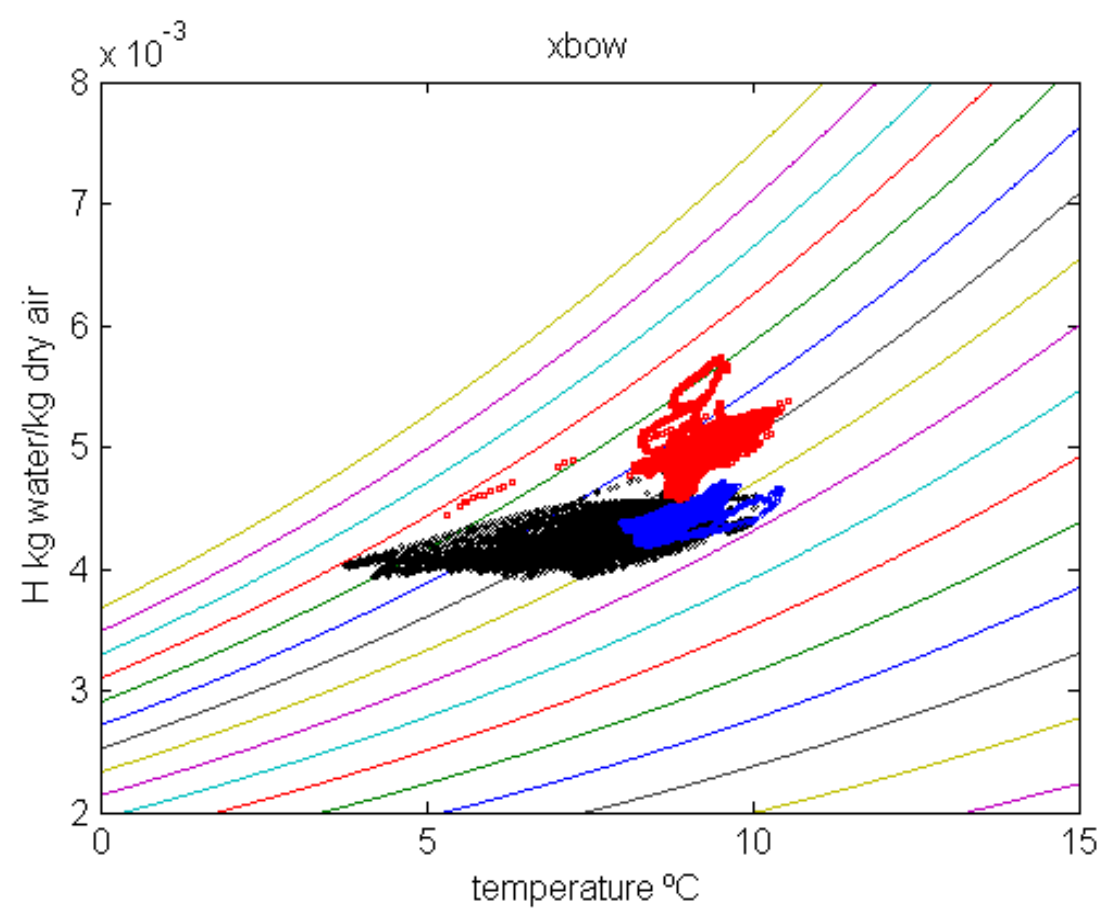

Figure4: Psychrometric chart $\left(\mathrm{T}-{ }^{\circ} \mathrm{C}-\right.$, absolute humidity - kg/kg dry air-) for Xbow motes in CWC. Color lines indicate relative humidity between $100 \%$ and $45 \%$ 